\title{
Giant Salivary Gland Calculi (GSGC): Report Of Two Cases
}

\author{
Giacomo Oteri ${ }^{1 *}$, Rosa Maria Procopio ${ }^{2}$ and Marco Cicciü ${ }^{3}$ \\ ${ }^{1}$ Oral Surgery Department, University of Messina, School of Dentistry, Messina, Italy \\ ${ }^{2}$ Oral Surgery Department, University of Messina, Italy \\ ${ }^{3}$ Oral Surgery and Oral Disease Department, University of Messina, School of Dentistry, Messina, Italy
}

\begin{abstract}
Sialolithiasis is the most common disease of salivary glands. It is a condition characterized by the obstruction of a salivary gland or its excretory duct due to the formation of calcareous concretions, resulting in salivary ectasia and even determining the subsequent dilatation of the salivary gland.
\end{abstract}

The sialolith usually measure from $1 \mathrm{~mm}$ to less than $10 \mathrm{~mm}$. They rarely measure more than $15 \mathrm{~mm}$. Infrequently giant salivary gland calculi (GSGC) $>15 \mathrm{~mm}$ have been reported in the literature. The submandibular gland and its duct appear to be the sites most susceptible to this disease.

The aims of this article were: 1) report the cases of two patients suffering of sialolithiasis caused by giant salivary gland calculi occurring in the Wharton's duct; and 2) present the results of the literature's research on giant sialolith.

The diagnostic approach of the two cases consisted of trans-occlusal endoral radiography, orthopantomography, CTscan. The patient's glands were treated with conservative trans-oral surgical technique stone removal in both cases, performed under local anaesthesia.

The glands recovered normal function quickly after removal of the stones.

For the patients the morbidity associated with salivary gland calculi removal follow-up showed asymptomatic and normally functioning glands.

Keywords: Giant salivary gland calculi.

\section{INTRODUCTION}

Salivary lithiasis is a condition characterized by the obstruction of salivary gland or its excretory duct by a calculus or sialolith associated with: swelling, pain, and infection of affected gland, resulting in salivary ectasia and even provoking the subsequent dilatation of the salivary gland [1].

The clinical symptoms are clear and allow for an easy diagnosis, whenever it must be taken into account that pain is only one of the symptoms and that it does not occur in $17 \%$ of the cases. Sialolithiasis accounts for $30 \%$ of salivary diseases and it most commonly involves the submandibular gland $(80 \%$ to $95 \%)$ and less frequently the parotid (5\% to $20 \%)$ The sublingual gland and the minor salivary glands are rarely (1\% to $2 \%)$ affected [2].

Sialolithiasis usually appears between the age of 30 and 60 years, and it is uncommon in children as only $3 \%$ of all sialolithiasis cases occur in the paediatric population [3]. It has a predilection for male patients, particularly in the case of parotid gland lithiasis [4].

The size of the salivary calculi may vary from less than $1 \mathrm{~mm}$ to a few $\mathrm{cm}$ in largest diameter. Most of the calculi $7.6 \%$ are larger than $15 \mathrm{~mm}$. Giant salivary gland calculi

*Address correspondence to this author at the Clinica Odontoiatrica Via Consolare Valeria - 98100 Messina, Italy; Tel: +3909040183;

Fax: 390902216010; E-mail: giacomo.oteri@unime.it
(88\%) are less than $10 \mathrm{~mm}$ in diameter [5], whereas only (GSGC) are considered rare, so they can be found in the literature in a few case reports only.

Different aetiological hypotheses have been put about salivary gland calculi: mechanical, inflammatory, chemical, neurogenic, infectious, strange bodies, etc. Anyway, it seems that the combination of a variety of these factors usually determines the precipitation of the amorphous tricalcic phosphate, which, once crystallized and transformed into hydroxyapatite becomes the initial focus [6]. From this moment on, it acts as a catalyst that attracts and supports the proliferation of new deposits of different substances.

Patients should be educated regarding the mechanism of their underlying pathology and methods of maintaining control over them by emphasizing the value of hydration and excellent oral hygiene, which lessens the severity of the attacks and prevents dental complications.

\section{CASE REPORTS}

We report the cases of two patients, presented to the Department of Dentistry of the University of Messina, because affected by acute pain and unilateral inflammation localized in the submandibular region.

Patient $\boldsymbol{A}$. Female 40 years old, healthy medical conditions, no smoker. The patient was referred from her dentist with a diagnosis of trigeminal pain, probably caused 


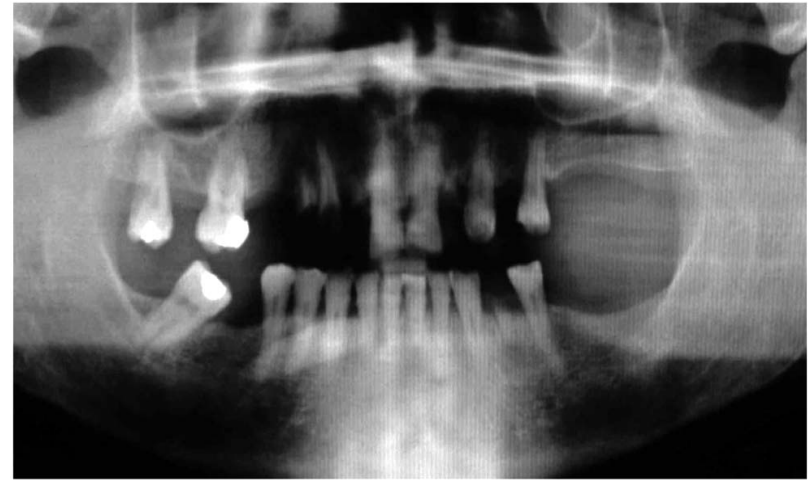

Fig. (1a). Orthopantomography showed long radiopaque mass appearing like an impacted lower right canine.

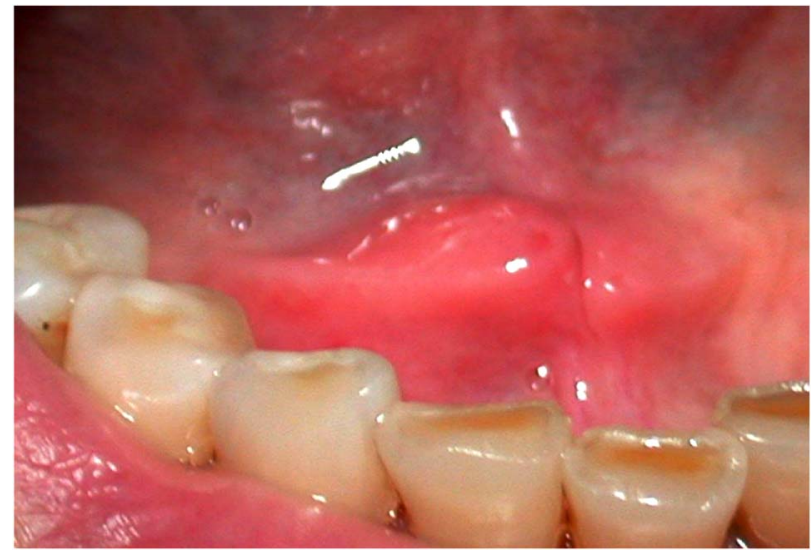

Fig. (1b). Preoperative intra-oral examination.

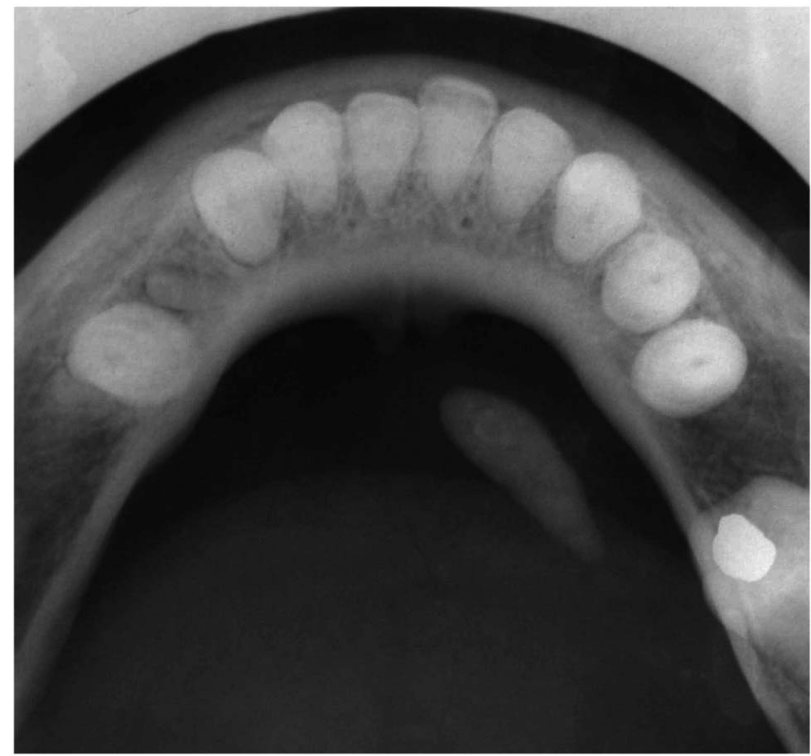

Fig. (1c). Trans-occlusal endoral radiography showed a radiopaque formation within the Wharton's right duct.

by an impacted tooth. In fact an orthopantomography, done 3 months before, showed a radiopaque area appearing like an impacted lower right canine (Fig. 1a). This kind of diagnosis could be common because the size and the location of the radiopaque area seem to be the same of a mandibular misplaced tooth.

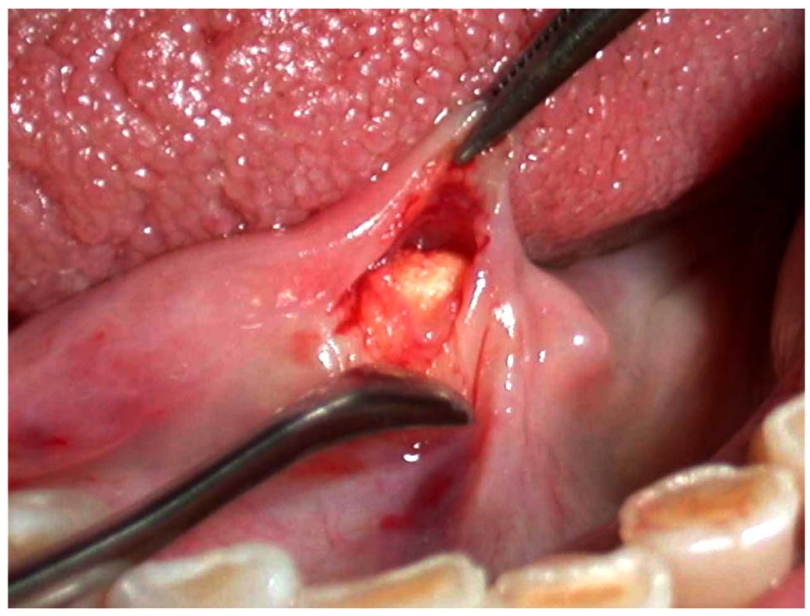

Fig. (1d). The orifice of the salivary duct was surgically enlarged with an about $8 \mathrm{~mm}$ long incision.

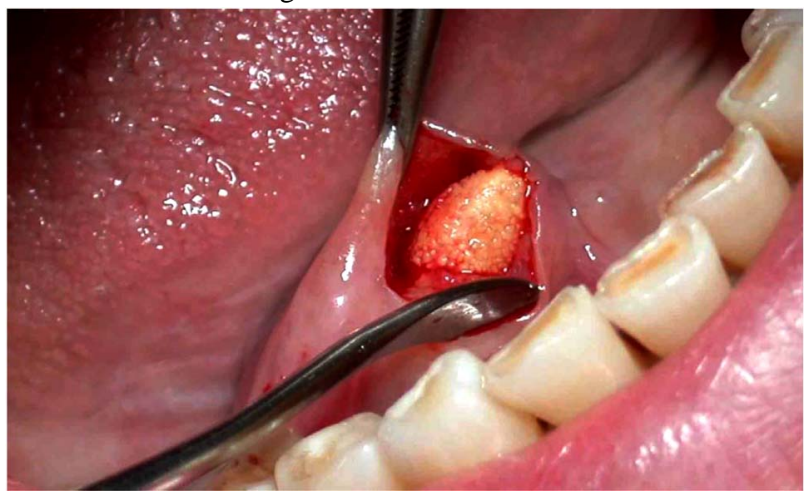

Fig. (1e). A small pressure exerted at the level of the distal ligature provoked the discharge of the sialolith through the incision.

She also referred from 21 days difficulty on breathing and foul-tasting mouth. She had a history of having episodes of left submandibular swelling occurring with meals. These symptoms disappeared within relatively short period, never more than 2 hours.

Intra-oral examination revealed a swelling localized in the right side of the floor of the mouth, solid to the touch and not adherent to any deeper structure (Fig. 1b).

The diagnosis of giant salivary calculus of the Wharton's duct was confirmed by intraoral Rx and TC scan that showed a radiopaque mineralized oval formation about $20 \mathrm{~mm}$ long and $6 \mathrm{~mm}$ large located within the Wharton's right duct (Fig. 1c).

N.S.A.I.D. and Antibiotics (Amoxicillin 1g 1x2 and ibuprofen $600 \mathrm{mg} \times 3$ ) were prescribed for a period of 6 days. Once the symptoms were controlled, the surgical removal of the calculus was planned.

Under regional anaesthesia, once the sialolith had been located, it was distally fixed with a suture in order to prevent any movement along the duct during the surgical procedure.

The orifice of the salivary duct was surgically enlarged with an about $8 \mathrm{~mm}$ long incision (Fig. 1d).

A small pressure exerted at the level of the distal ligature provoked the discharge of the sialolith through the incision (Fig. 1e). 


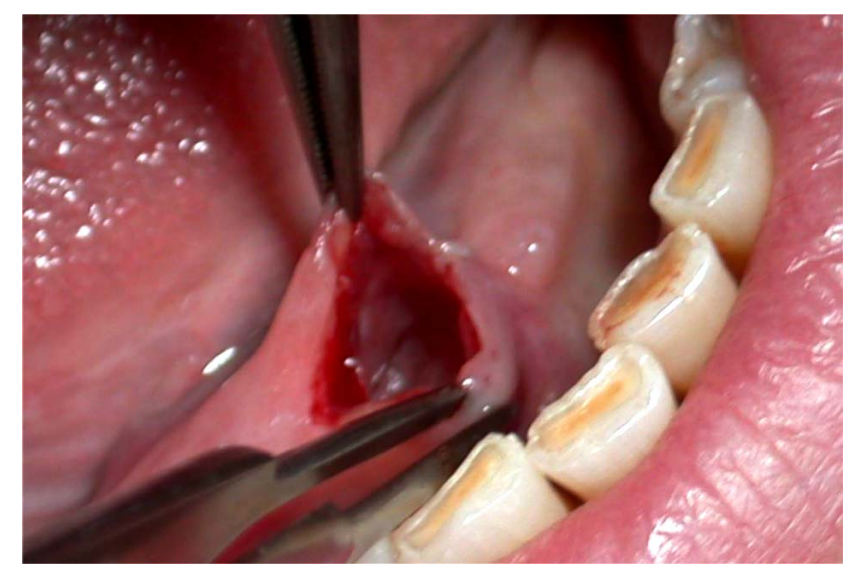

Fig. (1f). Warton's right duct after the sialolith removal.

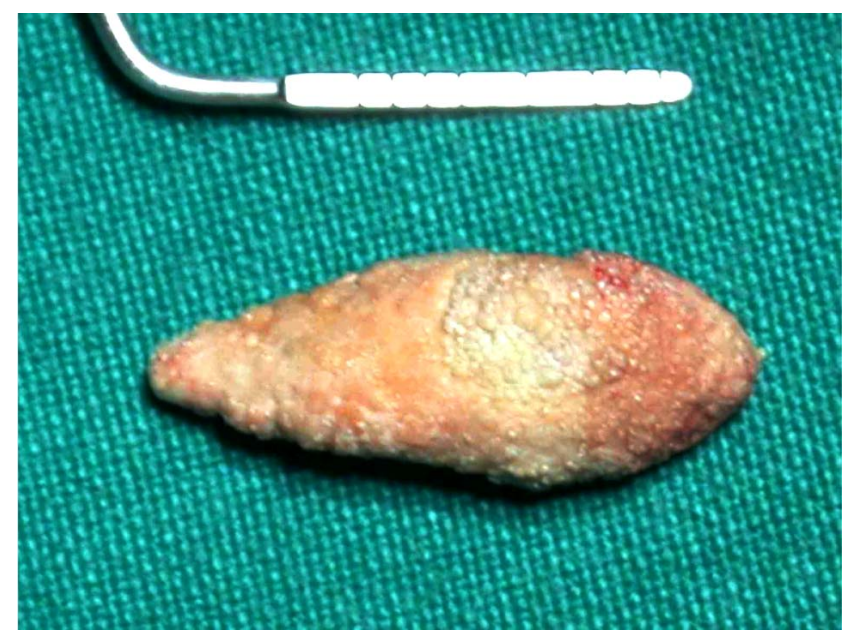

Fig. (1g). Giant Submandibular sialolith, measuring 20 x 6 mm.

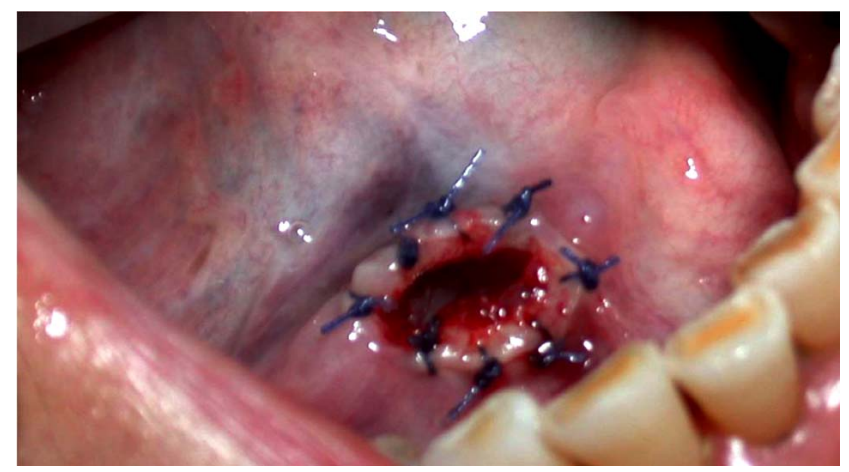

Fig. (1h). Incised mucosa was rotated outward with an everted suture in order to keep opened the ductal orifice.

When the sialolith was out (Fig. 1f-1g), the incised mucosa was rotated outward with an everted suture in order to keep opened the ductal orifice (Fig. 1h). The salivary flow immediately became regular.

Patient B. Female 51 years old, healthy medical conditions, smoker. Her physician referred the patient with this chief complaint: episodic acute pain in left submandibular area and swelling under the tongue. These phenomena were

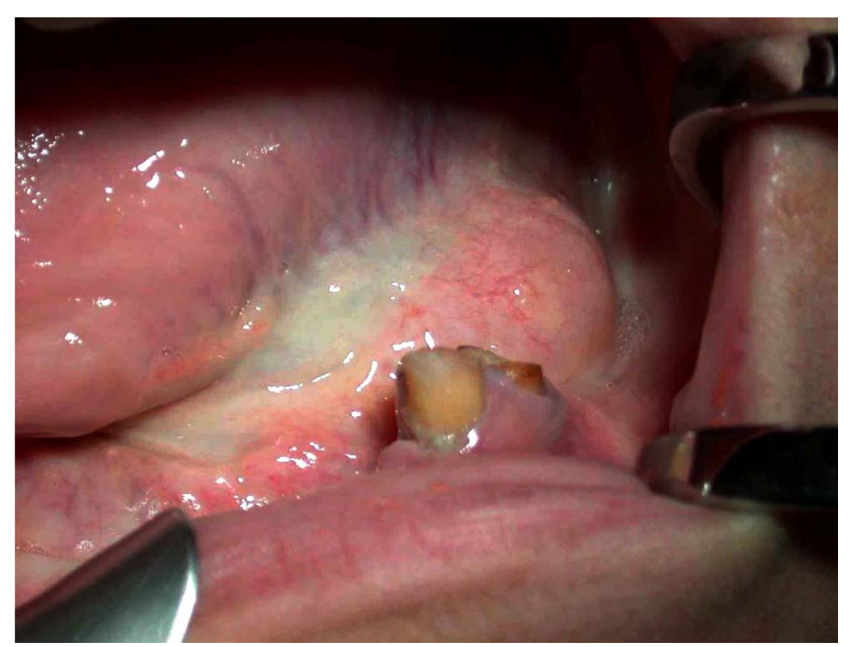

Fig. (2a). Preoperative intra-oral examination showed the asymmetric appearance of the swelled floor.

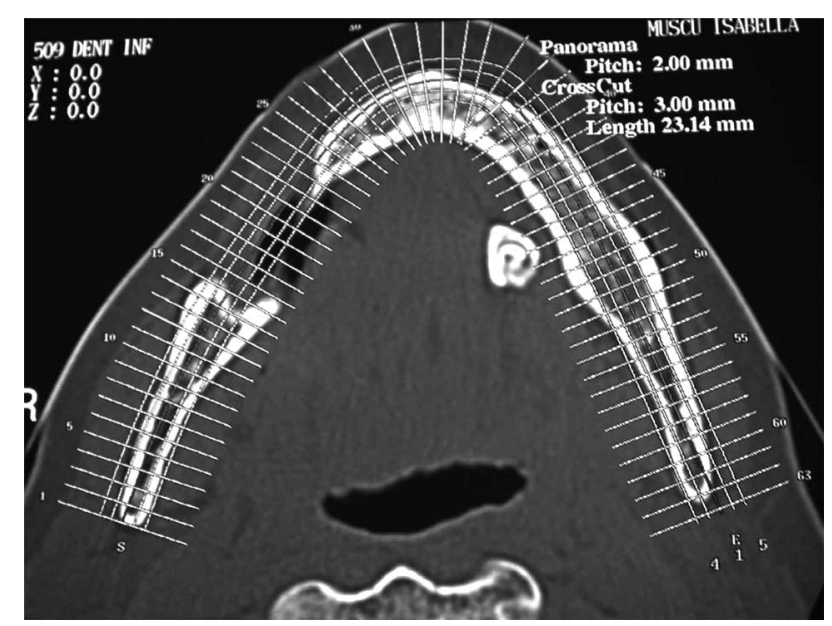

Fig. (2b). Axial CT-scan shows large radiopaque mass localized within the left Warton's duct.

observed at meal times and they remitted within a few hours. She noted also the presence of exudation in the oral cavity.

Intraoral examination showed the asymmetric appearance of the floor of the mouth (Fig. 2a). The palpation revealed the presence of a mobile solid formation, like a nut, under the left side of the tongue.

Remission of the infection was achieved after a 6 days therapy with Amoxicillin 1g 1x2 and ibuprofen 600mg x3.

A CT scan of mandibular region showed the presence of a rounded radiopaque sialolith with a diameter of $15 \mathrm{~mm}$., located within the Wharton's left duct (Fig. 2b).

Under local anaesthesia, an incision along the mucosa of the swelled floor opened the Warthon's duct creating a new larger access to oral cavity (Fig. 2c).

In this way the giant calculus was easily removed with a light pressure (Fig. 2d).

An everted suture of the incision was performed, in order to facilitate the formation of a salivary fistula (Fig. 2e-2f). 


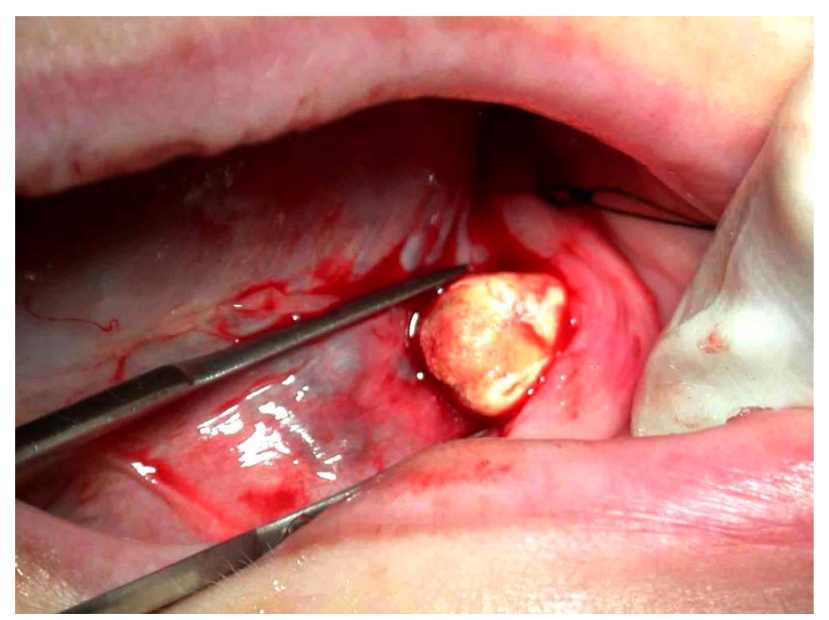

Fig. (2c). Incision along the mucosa of the mouth's floor opened the Warthon's duct.

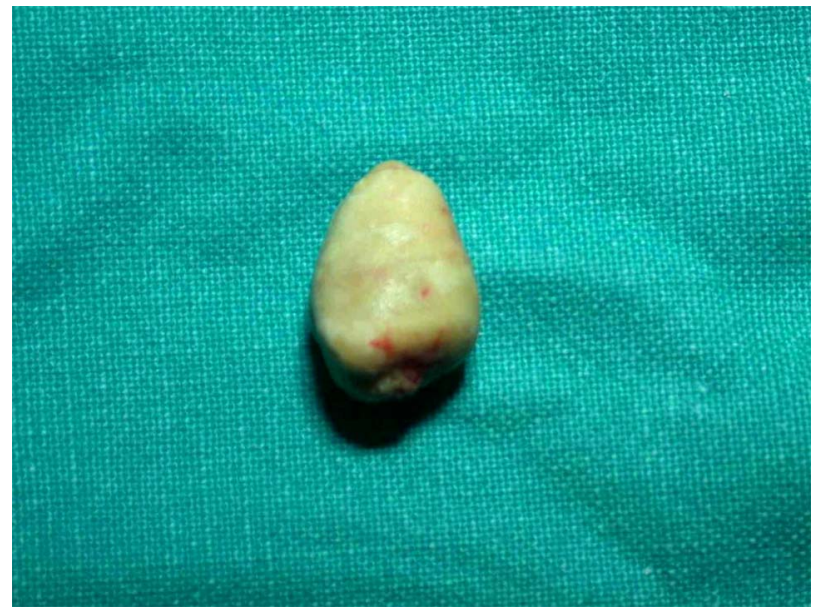

Fig. (2d). The sialolith with a diameter of $15 \mathrm{~mm}$.

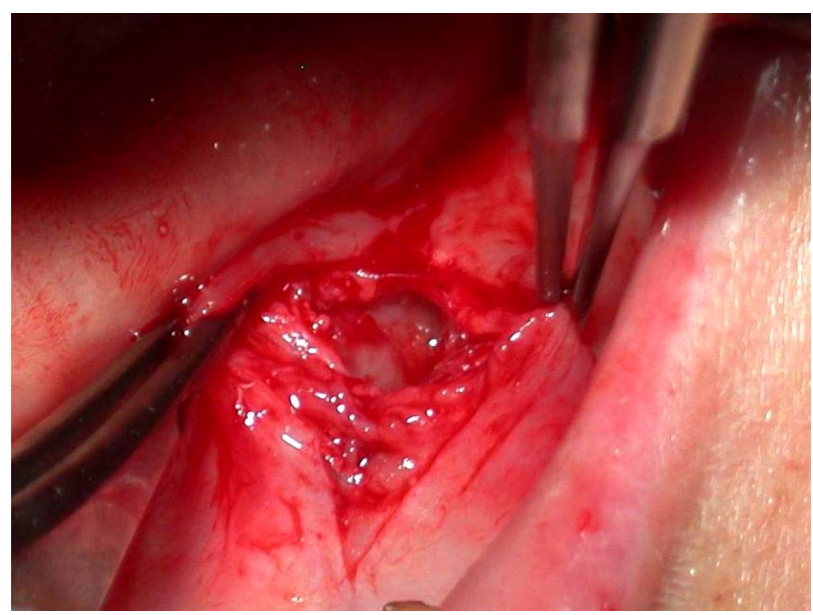

Fig. (2e). The left Warton's duct after sialolith removal.

In subsequent clinical follow-up the complete remission of the symptoms, the effectiveness of the salivary drainage and the normal functioning of the submandibular gland were observed.

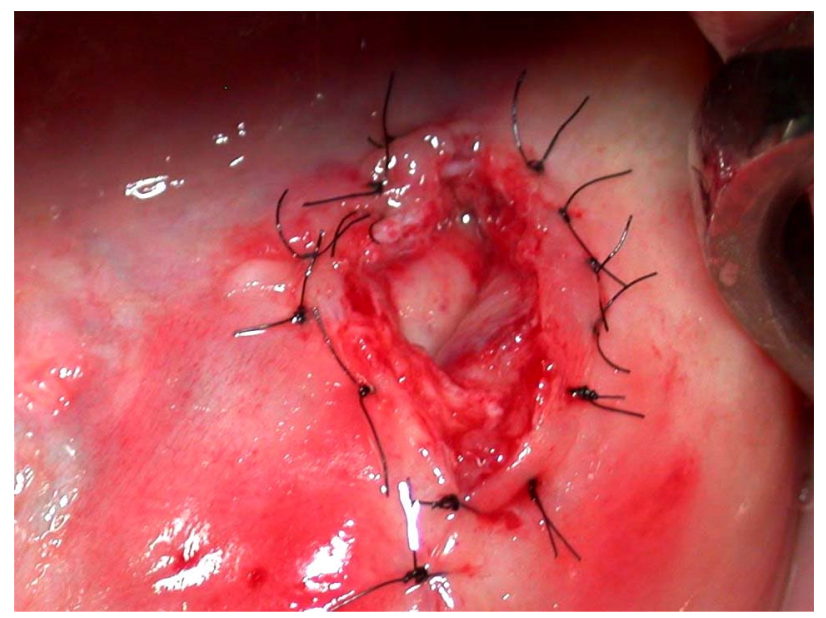

Fig. (2f). The suture of the incision was performed, in order to facilitate the formation of a salivary fistula.

\section{DISCUSSION}

Sialolithiasis is a pathological condition caused by the obstruction of a salivary gland or its excretory duct by a calculus [7].

Thanks to the stagnation of saliva rich in calcium, the sialolith is the result of the deposition of tricalcic phosphate salts around an initial nidus that consists of altered salivary mucin, desquamated epithelial cells and bacteria.

The ability of a calculus to grow and become a giant sialolith depends mainly on the affected duct's reaction.

When the sialolith is located in a duct able to dilate and to allow a normal secretion of salivary flow around the stone, the sialolith might increase in size, becoming a giant calculus, and remain asymptomatic for a long period [8].

Giant sialoliths are usually organized hard concretions, with a porous aspect, yellow colour and hard texture. They usually have an oval or long shape and in radiographic images they can appear like teeth.

Experimental studies have identified the increased salivary magnesium concentration as a key factor in determining the sialolithiasis [9].

The deposition of salivary calculi is not associated with systemic diseases involving calcium metabolism [10]. Gout is the only metabolic disease that predisposes, among others, to salivary stone formation. However, the gout calculi consist, typically, of urates. Sialoliths are ovoid or round, smooth or rough with a yellowish colour. They consist of calcium phosphate with small accounts of hydroxyapatite, magnesium, potassium and ammonia [11].

Bacterial infections are important factors involved into calculi's formation. Toxins produced by bacteria, can produce a local environment with $\mathrm{pH}$ less than 5.5, that causes tissue damage; when tissue healing processes re-estabilish the $7.2 \mathrm{pH}$ crystallization of salivary ions, especially calcium phosphates occurs [12].

The submandibular gland is more susceptible to the development of the salivary calculi than parotid gland because: 
- The Warthon's duct is longer and wider than /the Stensen's duct.

- The salivary flow is against gravity in the submandibular gland.

- The salivary submandibular $\mathrm{pH}$ is more alkaline and mucin proteins, calcium and phosphates are contained in greater amount than serous parotid saliva [13].

Regarding the diagnosis, in order to avoid that calculi remain unknown, is crucial to perform a careful history and to recognize clinical symptoms.

GCSC is characterized by salivary duct swelling, without any obvious reason or at meal times. The symptoms, referred by the patients during the meal times, are due to the higher stimulation of the salivary secretion and to the duct's obstruction that prevents its smooth flow. When affected by a salivary colic, the patient refers an acute pain, sense of swelling and pressure in the floor of the mouth.

The cases here reported (two female patients) are unusual, because the demographic data didn't coincide with those reported in literature (predilection for male patients ).

The pain referred by our patients was characteristic as the bad breath and foul-tasting mouth [2]. The swelling of the gland persisted and became indurated without recovering its normal size. Moreover our patients presented with an areas of fibrous swelling in the duct.

In some cases the bimanual posterior-anterior palpation of the mouth's floor allows to determine the presence of a giant calculus, which appears like a palpable mass.

The instrumental diagnosis of sialolithiasis is based on several imaging techniques. Ultrasonography represents an excellent first-level diagnostic technique because it reveals ductal and highly mineralized stones with a diameter of at least $1.5 \mathrm{~mm}$ with a accuracy of $99 \%$ [14].

Conventional intra-oral X-ray may be more useful than extra-oral radiography, particularly trans-occlusal endoral radiography.

Sialography is an adequate technique to detect salivary gland calculi that allows the visualization of the whole duct system. However, sialography is not indicated in the case of acute infections or patients sensible to contrast medium. Whether a radiopaque calculus is observed in the distal portion of the duct sialography should not be used, because the injected contrast medium could move the calculus to the proximal portion, near the gland, complicating its removal.

Scintigraphy could be performed in the event of a suspected sialolithiasis, when sialography is not indicated and in patients with no permeable glandular ducts.

Computerized tomography and nuclear magnetic resonance have changed the imaging techniques of detection of sialoliths. CT-Scan has become the rx examination of choice to detect gland salivary sialolith, because not invasive like sialography.

Sialoendoscopy is a new diagnostic means of directly visualising intra-ductal stones that has bridged the diagnostic gap between the clinical suspicion of salivary obstruction and the limitations of conventional radiology [15].
In the above reported cases intraoral $\mathrm{Rx}$ and $\mathrm{TC}$ scan were successfully adopted. The treatment of choice of small sialolith should be medical instead of surgical. However, if the calculus is of a medium or large size, like the giant salivary gland calculi, a salivary colic may occur and the sialolith cannot be expelled spontaneously.

The ultimate objective of giant sialoliths treatment is restoring a normal salivary flow. Whenever the stone can be palpated intraorally, the best option is to remove it through an intraoral approach [16]. The choice of a surgical approach to access the sialolith with submandibular gland preservation requires careful imaging evaluation and minimal invasive removal, transoral sialolithomy. After surgical calculi removal the patients show asymptomatic and normally functioning glands in a short time [17].

The clinicians should evaluate carefully the painful or painless swellings in submandibular area. This condition seems to be the most common disease in submandibular gland and Wharton's duct due to the presence of gland lithias. Large submandibular sialoliths should be treated by appropriate approach to avoid possible severe post op complications [18]. The two cases show how a no invasive surgery technique can be performed without opening large flap respecting the soft tissue of the treated area.

A diet rich in proteins and liquids including acid food and drinks is also advisable in order to prevent the formation of further new sialolith into the salivary gland.

\section{CONCLUSION}

Giant salivary gland calculi ( $>15 \mathrm{~mm}$ ) are considered rare; for this reason they can be found in the literature in a few case reports.

GSGC might be asymptomatic or in the most cases the patient presents episodes of salivary colic characterized by pain, localized in area of the stone, exudation and swelling in the oral cavity. Surgical treatment has traditionally been used as therapy to restore a physiologic salivary flow.

The presented cases showed how practitioners should perform all the instrumental and clinical investigations in order to avoid misdiagnosis.

\section{REFERENCES}

[1] Ledesma-Montes C, Garcés-Ortìz M, Salcido-Garcìa JF, et al. Giant sialoloth : case report and review of the literature. J Oral Maxillofac Surg 2007; 65: 128-30.

[2] Lustman J, Regev E, Melamed Y. Sialolithiasis: a survey on 245 patients and review of the literature. Int J Oral Maxillofac Surg 1990; 19: 135-38.

[3] Nahalieli o, Eliav E, Hasson O, Zagury A, Baruchin AM. Pediatric sialolithiasis. Oral Surg Oral Med Oral Pathos Oral Radiol Endod 2000; 90: 709-12.

[4] Bodner L. Giant salivary gland calculi: Diagnostic imaging and surgical management. Oral Surg Oral Med Oral Pathol Oral Radiol Endod 2002; 94: 320-23.

[5] Batori M, Mariotta G, Chatelou H, et al. Diagnostic and surgicalo managemjent of submandibular gland sialolithiasis: Report of a stone of unusual size. Eur Rev Med Pharmacol Sci 2005; 9: 67-8.

[6] Bodner L. Parotid sialolithiasis. J Laryngol Otol 1999; 113: 266-67.

[7] Epker BN. Obstructive and inflammatory disease of the major salivary glands. Oral Surg Oral Med Pathol 1972; 33: 2-27.

[8] Manjunath R, Burman R. Giant submandibular sialolith of remarkable size in the comma area of Wharton's Duct : a case report. J Oral Maxillofac Surg 2009; 67: 1329-32. 
[9] Grases F, Santiago C, Simonet BM, Costa-Bauza A. Sialolithiasis: Mechanism of calculi formation and etiologic factors. Clin Chim Acta August 2003; 334: 131-6.

[10] Williams M F. Sialolithisis. Otolaryngol Clin of North Am 1999; 32: 819-34.

[11] Work WP, Hecht DW. Inflammatory diseases of the major salivary glands. Papperalla MM, Shumrick DF, Eds. Philadelphia, W.B Saunders. Otolaryngology 1980; 3: 2235-43.

[12] Escudier MP. The current status and possible future of salivary calculi. In: Pregrel M, Ed. Atlas of oral and maxillofacial surgery clinics of North America. Philadelphia, PA: Saunders 1998; p. 11732.

[13] Raksin SZ, Gould SM, William AC. Submandibular gland sialolith of unusual size and shape. J oral Surg 1975; 33: 142-45.
[14] Yoshimura Y, Inoue Y, Odagawa T. Sonographic examination of sialolithiasis. J Oral Maxillofac Surg 1989; 47: 907-12.

[15] Cappaccio P, Torretta S, Ottaviani F, Sambataro G, Pignataro L. Modern management of obstructive salivary disease. Acta Otorhinolaryngol Ital 2007; 27: 161-72.

[16] McGurk M, Escudier MP, Brown JE. Modern management of salivary calculi. Br J Surg 2005; 92: 107-12.

[17] McGurk M, Makdissi J, Brown JE. Intra-oral removal pf stones from the hilum of the submandibular gland: report of technique and morbidity. Int J Oral Maxillofac Surg 2004; 33: 683-6.

[18] Alkurta MT, Pekerb I. Unusually large submandibular sialoliths: report of two cases. Eur J Dent 2009; 3(2): 135-39.

(C) Oteri et al.; Licensee Bentham Open.

This is an open access article licensed under the terms of the Creative Commons Attribution Non-Commercial License (http://creativecommons.org/licenses/by-nc/3.0/) which permits unrestricted, non-commercial use, distribution and reproduction in any medium, provided the work is properly cited. 